\title{
BIOSYNTHESIS OF FORMYCIN \\ INCORPORATION AND DISTRIBUTION OF LABELED COMPOUNDS INTO FORMYCIN
}

\author{
Kōzō Ochi, Shintarō Kikuchi*, Shigetaka Yashima \\ and Yoshitomo EGUCHI \\ Department of Microbial Engineering and Technology, \\ Faculty of Agriculture, Hokkaido University, \\ Sapporo, Japan
}

(Received for publication March 19, 1976)

\begin{abstract}
1. Two carbons, carbon-2 and one of carbons-3 to -5 , of lysine seemed likely to be incorporated into one of carbon of the chromophore moiety of formycin.

2. From the results of radioisotopic studies with glutamate, $\gamma$-amino- $n$-butyrate or organic acids related to tricarboxylic acid cycle, the important role of glutamate in the biosynthesis of formycin was strongly suggested.

3. The incorporation of nitrogen(s) of lysine into three nitrogens, including two nitrogens of pyrazole ring, of formycin was suggested by mass spectroscopy.

4. Ribose was estimated as a direct precursor for the ribosyl moiety of formycin, whereas the biosynthesis of ribose was shown to occur via the pathway other than hexose monophosphate shunt or glucuronate pathway.

5. In replacement culture, the salvage synthesis of formycin from its chromophore moiety was not observed and it was also evident that the chromophore moiety or pyrazofurin (pyrazomycin) inhibited the biosynthesis of formycin.
\end{abstract}

There have been several investigations on the biosynthesis of C-riboside nucleosides, i.e., pseudouridine, showdomycin, minimycin, pyrazofurin (pyrazomycin) and the formycin family. In the biosynthesis of pseudouridine, the intramolecular rearrangement in tRNA of uridylate to pseudouridylate has been strongly suggested. ${ }^{1 \sim 8)}$ The biosynthesis of showdomycin has been well established and confirmed to occur by the condensation of ribose and an asymmetric four-carbon dicaboxylic acid. ${ }^{7 \sim 10)}$ Recently, studies on the biosynthesis of minimycin revealed a novel mechanism whereby C-riboside linkage is formed from sedoheptulose 7-phosphate (or eight-carbon branched chain sugar phosphate). ${ }^{11)}$ C-Riboside linkage of pyrazofurin was also believed to be formed by this mechanism. ${ }^{11}$ )

The biosynthesis of formycin by Nocardia interforma has been proposed to occur via a pathway other than that of biosynthesis of purine nucleotide while exogeneously added ribose was estimated to be incorporated into the ribosyl moiety of formycin. ${ }^{12)}$ It was also reported that formycin may be formed from formycin $5^{\prime}$-monophosphate then deaminated to formycin B. ${ }^{13)}$ Using Streptomyces sp. MA406-A-1, a formycin-producing strain, we reported that carbon atom from lysine, glutamate and/or aspartate was incorporated into formycin with high efficiency, and that novel enzyme(s) catalyzing the amination of formycin $\mathbf{B}$ to formycin was present in this organism. ${ }^{14,15)}$ To elucidate the more detailed mechanism of formycin biosynthesis, we examined the incorporation and the distribution of various labeled compounds into formycin and this paper presents the results of these studies.

* Present address. Faculty of Pharmaceutical Sciences, Hokkaido University, Sapporo, Japan 


\section{Materials and Methods}

Organisms and Cultivation

Streptomyces sp. MA406-A-1 and Xanthomonas oryzae were obtained from the Institute of Microbial Chemistry, Tokyo. Cultivation of the Streptomycete was carried out for $10 \sim 12$ hours in a maltosepeptone-yeast extract medium (MPY-medium) and the washed cells prepared from the cultured broth were used in the replacement culture at $27^{\circ} \mathrm{C}$ with $50 \mathrm{ml}$ of glucose-lysine- $\mathrm{NH}_{4} \mathrm{Cl}$ medium (GL-medium) as previously described ${ }^{14}$. When ${ }^{14} \mathrm{C}$-labeled compounds were used in the experiments, $5 \mu \mathrm{Ci}$ of each compound were added to $50 \mathrm{ml}$ of GL-medium with exception of adding $10 \mu \mathrm{Ci}$ of DL-lysine.

Degradation of Formycin

7-Amino-3-carboxypyrazolo[4,3-d]pyrimidine (DFA-3) and 7-amino-pyrazolo[4,3-d]pyrimidine (DFA-4) were prepared by the chemical degradation of formycin according to an improved technique (personal communication from Dr. K. KawAmura) of KawamurA et al. ${ }^{16)}$ The degradation steps were as follows:

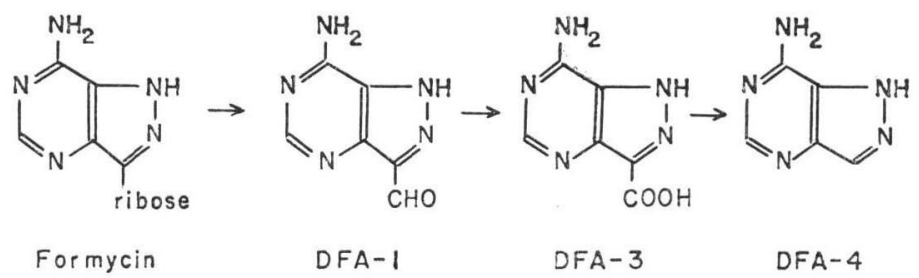

One gram of formycin was dissolved in $100 \mathrm{ml}$ of $6 \%$ sodium periodate and the solution was kept for a week at $0 \sim 5^{\circ} \mathrm{C}$. Pale yellowish precipitates that formed were collected on a glass filter (G-4) and dried at room temperature to yield $300 \mathrm{mg}$ of amorphous powder (7-amino-3-aldehyde-pyrazolo[4,3-d]pyrimidine, DFA-1). DFA-1 (300 mg) was dissolved in $30 \mathrm{ml}$ of $0.1 \mathrm{~N} \mathrm{NaOH}$ on a boiling waterbath and allowed to stand for $2 \sim 3$ days at room temperature. The crystals usually appeared though in certain cases, the crystals did not appear. The crystals were dissolved on a boiling water-bath and the $\mathrm{pH}$ value of the warm solution was adjusted to 5.0 with $2 \mathrm{~N} \mathrm{HCl}$. After keeping the acidified solution overnight at $0 \sim 5^{\circ} \mathrm{C}$, the precipitates that formed were collected and dried at room temperature to yield $200 \mathrm{mg}$ of pale yellowish powder (DFA-3). DFA-3 $(200 \mathrm{mg}$ ) thus prepared was mixed with $20 \mathrm{ml}$ of quinoline and $20 \mathrm{mg}$ of copper powder and reflexed for 1 hour. After filtration, the filtrate was mixed with $80 \mathrm{ml}$ of benzene and $20 \mathrm{ml}$ of $0.1 \mathrm{~N} \mathrm{NaOH}$ and the mixture was shaken vigorously. After discarding the benzene layer, the water layer was washed twice with $40 \mathrm{ml}$ each of benzene and adjusted to give $\mathrm{pH} 6$ to 7 with $2 \mathrm{~N} \mathrm{HCl}$. The aqueous solution was applied on a column $(\phi 1 \mathrm{~cm} \times 8 \mathrm{~cm})$ of active charcoal and the column was washed with $30 \mathrm{ml}$ of water. The column was eluted with $50 \%$ aqueous acetone and the eluate was cut into $5-\mathrm{ml}$ fractions. The appropriate fractions showing maximum absorption at $291 \mathrm{~nm}$ were pooled and evaporated in vacuo at $40^{\circ} \mathrm{C}$ to yield $58 \mathrm{mg}$ of white powder (DFA-4). Fig. 1 shows the ultraviolet spectra of DFA-3 and -4 in $0.1 \mathrm{~N} \mathrm{NaOH}$ and these spectra coincided with those observed by Dr. KaWAMURA (personal communications). Melting points of DFA-3 and -4 were identical with those reported. ${ }^{10)}$ From NMR spectra and mass spectrometries, it was also confirmed that DFA-3 and -4 were identical with 7-amino-3carboxypyrazolo[4,3-d]pyrimidine and 7-aminopyrazolo[4,3-d]pyrimidine, respectively.

\section{Determinations}

Formycin accumulated in the media was determined by a cylinder-plate method with $X$.

Fig. 1. Ultraviolet spectra of DFA-3 and DFA-4 in $0.1 \mathrm{~N} \mathrm{NaOH}$

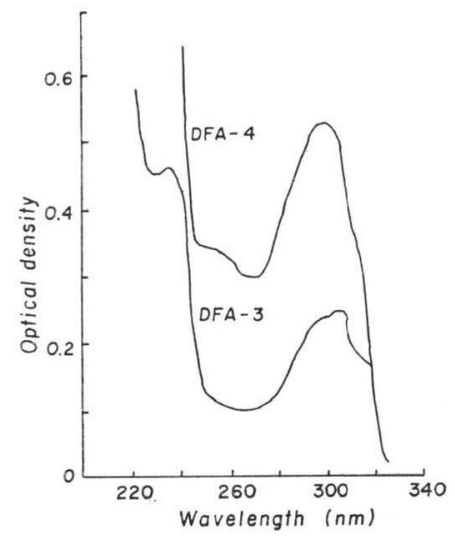


oryzae as a test organism.

As previously reported, specific radioactivity of formycin was calculated after the column chromatography with Dowex $1 \times 4 .{ }^{14)}$ For the degradation studies, the fractions containing formycin in the column chromatography were applied to a column $(\phi 1 \mathrm{~cm} \times 7 \mathrm{~cm})$ of Dowex $50 \mathrm{~W} \times 4(200 \sim 400 \mathrm{mesh})$ in the $\mathrm{H}^{+}$form. After wasing with $50 \mathrm{ml}$ of water, formycin was eluted with $0.1 \mathrm{~N} \mathrm{NH}_{4} \mathrm{OH}$ and evaporated to dryness (white powder) in vacuo at $40^{\circ} \mathrm{C}$. Formycin thus prepared was degradated to DFA-3 and -4 , and when radioactive formycin was prepared, $100 \sim 300 \mathrm{mg}$ of nonradioactive authentic formycin were added as carrier in the degradation. Specific radioactivity of DFA-3 or -4 was determined by measuring the radioactivity and concentration of these compounds in $0.1 \mathrm{~N} \mathrm{NaOH}$. The radioactivities were measured in a liquid scintillator reported previously. ${ }^{14)}$ The concentrations were calculated using the molar extinction coefficients (DFA-3, $\varepsilon_{300 \mathrm{~nm}}=8,410$; DFA-4, $\varepsilon_{300 \mathrm{~nm}}=5,540$ ) determined by KAWAMURA et al. ${ }^{1{ }^{13}}$

Resolution of DL-Lysine

Chemical resolution of DL-lysine was carried out with DL-[2- $\left.{ }^{14} \mathrm{C}\right]$ lysine and nonradioactive Lglutamate according to the method of Емміск. ${ }^{17)}$ The resolution product was identical with an authentic L-lysine-L-glutamate when compared by infrared spectrum and melting point.

Reagents and Analytical Measurements

${ }^{15} \mathrm{NH}_{4} \mathrm{Cl}$ was obtained from Stohler Isotope Chemicals Ltd. ${ }^{14} \mathrm{C}$-Labeled compounds were purchased from Daiichi Pure Chemicals Co., Ltd., and L-lysine-L-glutamate was from Sigma Chemical Co., Ltd. Pyrazofurin was kindly gifted by Dr. G. E. Gutowski of the Lilly Research Laboratories. All other reagents were of analytical grade.

Ultraviolet spectra were obtained with a Hitachi spectrophotometer model 124. Radioactivities were measured in an Aloka liquid scintillation counter model LSC-502 using the liquid scintillator described previously. ${ }^{14)}$ Infrared spectra were obtained by a Hitachi infrared spectrophotometer model EPI-S2 with $\mathrm{KBr}$ tablets. Mass spectra studies were done with a Hitachi mass spectrometer model RNS-4. NMR spectra were determined on a Hitachi NMR spectrometer $(90 \mathrm{MHz})$.

\section{Results}

Incorporation and Distribution of ${ }^{14} \mathrm{C}$-Labeled Lysine into Formycin

Since our previous work suggested that lysine may be closely related to the biosynthesis of formycin, ${ }^{14)}$ the distribution of ${ }^{14} \mathrm{C}$ in formycin from $\left[\mathrm{U}-{ }^{14} \mathrm{C}\right]$ lysine or $\left[\mathrm{U}-{ }^{14} \mathrm{C}\right]$ glucose was examined in the replacement culture with GL-medium. Table 1 shows that ${ }^{14} \mathrm{C}$ from lysine incorporated into formycin was exclusively located at the chromophore moiety of formycin (DFA-4) and about three-fourths of ${ }^{14} \mathrm{C}$ from glucose were distributed in the ribosyl moiety. As shown in Table 2, the ratios of the incorporation of ${ }^{14} \mathrm{C}$ from DL- or L-[2- $\left.{ }^{14} \mathrm{C}\right]$ lysine to that of ${ }^{14} \mathrm{C}$ from L-[U- $\left.{ }^{14} \mathrm{C}\right]$ lysine were approximately $1: 2$ under the all experimental conditions examined. It was also confirmed that little or no radioactivity

Table 1. Incorporation and distribution of labeled substrate into formycin after 2 hours of replacement culture

\begin{tabular}{l|c|c|c|c}
\hline \multirow{2}{*}{$\begin{array}{c}\text { Substrate used } \\
\text { incorporation* }\end{array}$} & DFA-4 & $\begin{array}{c}\text { P-1' in } \\
\text { ribose }\end{array}$ & $\begin{array}{c}\text { Percent distribution** of }{ }^{14} \mathrm{C} \text { in } \\
\text { in ribose }\end{array}$ \\
\cline { 2 - 5 } & 11 & 99 & 0 & 1 \\
{$\left[\mathrm{U}-{ }^{14} \mathrm{C}\right]$ Lysine } & 52 & 26 & 20 & 54 \\
\hline $\left.\mathrm{U}^{14} \mathrm{C}\right]$ Glucose & & 26 & \\
\hline
\end{tabular}

* Specific radioactivity of C-atom in formycin Specific radioactivity of $\mathrm{C}$-atom in labeled substrate $\times 100$

** Calculated from specific radioactivities of formycin, DFA-3 and DFA-4. 
appeared in formycin when DL- $\left[1-{ }^{14} \mathrm{C}\right]$ or -[6${ }^{14} \mathrm{C}$ llysine was used under the same conditions as those of experiment 1 in Table 2 . These results made it likely that two carbons of lysine, i.e., carbon- 2 and one of carbons- 3 to -5 of lysine, were incorporated into the chromophore moiety of formycin.

Incorporation and Distribution of Labeled

Organic Acids or Glutamate into Formycin

As reported previously, ${ }^{14} \mathrm{C}$ from [U${ }^{14} \mathrm{C}$ glutamate was incorporated into formycin with relatively high efficiency. ${ }^{14)}$ As can be seen in Table 3, three-fourths of ${ }^{14} \mathrm{C}$ from [U${ }^{14} \mathrm{C}$ glutamate incorporated were located at the chromophore moiety of formycin and the incorporation of the ${ }^{14} \mathrm{C}$ did not decrease even in the presence of nonradioactive fumarate, or $\gamma$-amino- $n$-butyrate which is known as one of metabolic products of glutamate. It was also evident that the incorporation of ${ }^{14} \mathrm{C}$ from $\left[2-{ }^{14} \mathrm{C}\right]$ acetate, $\left[2,3-{ }^{14} \mathrm{C}\right]$ succinate or $\left[2,3-{ }^{14} \mathrm{C}\right]$ fumarate was more efficiently than that of ${ }^{14} \mathrm{C}$ from $\left[1-{ }^{14} \mathrm{C}\right]$ acetate, $\left[1,4-{ }^{14} \mathrm{C}\right]$ acetate, $\left[2,3-{ }^{14} \mathrm{C}\right]$ succinate or $\left[2,3-{ }^{14} \mathrm{C}\right]$ fumarate was more efficiently than that of ${ }^{14} \mathrm{C}$ from $\left[1-{ }^{14} \mathrm{C}\right]$ acetate, $\left[1,4-{ }^{14} \mathrm{C}\right]$ succinate or $\left[1,4-{ }^{14} \mathrm{C}\right]$ fumarate, respectively, and that the incorporation of ${ }^{14} \mathrm{C}$ from $\left[2,3-{ }^{14} \mathrm{C}\right]$ fumarate decreased in the presence of nonradioactive glutamate. As the sum of values for percent incorporation of $\left[1-{ }^{14} \mathrm{C}\right]$ and $\left[2-{ }^{14} \mathrm{C}\right]$ acetate, $\left[1,4-{ }^{14} \mathrm{C}\right]$ and $[2,3-$ $\left.{ }^{14} \mathrm{C}\right]$ succinate or $\left[1,4-{ }^{14} \mathrm{C}\right]$ and $\left[2,3-{ }^{14} \mathrm{C}\right]$ fumarate can be considered to be equal to the values of [U$\left.{ }^{14} \mathrm{C}\right]$ acetate, $\left[\mathrm{U}-{ }^{14} \mathrm{C}\right]$ succinate or $\left[\mathrm{U}-{ }^{14} \mathrm{C}\right]$ fumarate, respectively, glutamate seemed to be the most efficient precursor among the compounds tested for the biosynthesis of formycin. In addition, the incorporation

Table 3. Incorporation and distribution of labeled compounds into formycin after 2 hours of replacement culture

\begin{tabular}{|c|c|c|}
\hline $\begin{array}{l}\text { Labeled compound added } \\
\qquad(2 \mathrm{~mm})\end{array}$ & $\begin{array}{c}\text { Percent } \\
\text { incorporation* }\end{array}$ & $\begin{array}{l}\text { Percent distribution* } \\
\text { of }{ }^{14} \mathrm{C} \text { to DFA-4 }\end{array}$ \\
\hline$\left[1-{ }^{14} \mathrm{C}\right]$ Acetate & 0.7 & $* *$ \\
\hline$\left[2-{ }^{14} \mathrm{C}\right]$ Acetate & 2.0 & 59 \\
\hline$\left[1,4-{ }^{14} \mathrm{C}\right]$ Succinate & 1.7 & $* *$ \\
\hline$\left[2,3-{ }^{14} \mathrm{C}\right]$ Succinate & 4.6 & ** \\
\hline$\left[1,4-{ }^{14} \mathrm{C}\right]$ Fumarate & 1.1 & 52 \\
\hline$\left[2,3-{ }^{14} \mathrm{C}\right]$ Fumarate & 3.9 & 57 \\
\hline + Glutamate*** & 2.4 & $* *$ \\
\hline$\left[\mathrm{U}-{ }^{14} \mathrm{C}\right]$ Glutamate & 11.6 & 72 \\
\hline+ Fumarate $* * *$ & 10.6 & $* *$ \\
\hline+ Succinate $* * *$ & 9.4 & $* *$ \\
\hline$+\gamma$-Amino- $n$-butyrate ${ }^{* * *}$ & 13.4 & $* *$ \\
\hline$\left[\mathrm{U}-{ }^{14} \mathrm{C}\right]$ Glycine & 2.5 & $* *$ \\
\hline
\end{tabular}

* Calculated as described in Table 1 .

** Experiment was not done.

*** Nonradioactive compound was added at a concentration of $5 \mathrm{~mm}$.
Table 2. Incorporation of labeled lysine into

\begin{tabular}{l|c|c|c|c|}
\hline \multirow{2}{*}{$\begin{array}{c}\text { Labeled lysine } \\
\text { used }\end{array}$} & \multicolumn{4}{|c}{ Percent incorporation* } \\
\cline { 2 - 5 } & Exp. 1 & Exp. 2 & Exp. 3 & Exp. 4 \\
\hline $\begin{array}{c}\text { L-[U- }{ }^{14} \text { C] } \\
\text { Lysine } \\
\begin{array}{c}\text { DL-[2-14 C] } \\
\text { Lysine } \\
\text { L-[2- }{ }^{14} \text { C] } \\
\text { Lysine }\end{array}\end{array}$ & 13.9 & 8.7 & 14.8 & 10.3 \\
\hline
\end{tabular}

* Calculated as described in Table 1.

* In experiment 1 , L-or DL-lysine was added at 10 or $20 \mathrm{mM}$, in experiment 2, L-or DLIn experiment 3 or 4, L-lysine was added at 20 or $5 \mathrm{~mm}$, respectively.

*** Experiment was not done. 
of ${ }^{14} \mathrm{C}$ from $\left[\mathrm{U}^{-14} \mathrm{C}\right]$ glutamate did not decrease in the presence of nonradioactive aspartate, while ${ }^{14} \mathrm{C}$ from $\left[\mathrm{U}-{ }^{14} \mathrm{C}\right]$ aspartate decreased to one-half in the presence of nonradioactive glutamate in the replacement culture for 9 hours.

\section{Incorporation and Distribution of ${ }^{15} \mathrm{~N}$ from ${ }^{15} \mathrm{NH}_{4} \mathrm{Cl}$ into Formycin}

To estimate which nitrogen source in GL-medium, lysine or $\mathrm{NH}_{4} \mathrm{Cl}$, would function as nitrogen donor in the biosynthesis of formycin, ${ }^{14} \mathrm{NH}_{4} \mathrm{Cl}$ was replaced by ${ }^{15} \mathrm{NH}_{4} \mathrm{Cl}$ (95 atom \%) and the replacement culture was carried out for 2 hours. Formycin accumulated was isolated and analyzed by mass spectroscopy on the basis of mass-spectral data presented by TOWNSEND and RoBINs. ${ }^{18)}$ The spectra in Fig. 2 show that, when ${ }^{15} \mathrm{NH}_{4} \mathrm{Cl}$ was used, the base peak observed at $\mathrm{m} / \mathrm{e} 164$ shifted to $\mathrm{m} / \mathrm{e} 166$ whereas peak at $m / e 53$ was not changed. The base peak (chromophore +30 ; diagnostic ion for $\mathrm{C}$ ribonucleoside) and peak at $m / e 53$ have been assigned as I and II (Fig. 2), respectively. ${ }^{18)}$ No or little formation of formycin was observed in the replacement culture with GL-medium from which lysine or $\mathrm{NH}_{4} \mathrm{Cl}$ was omitted. These results suggested that two nitrogens in aminopyrimidine moiety of formycin were derived from $\mathrm{NH}_{4} \mathrm{Cl}$, so that, three nitrogens of formycin including two nitrogens in the pyrazole moiety were derived from nitrogen(s) of lysine. The shift of base peak to the peak at $m / e 166$ disappeared, as shown in Fig. 3, in the experiment with use of GL-medium containing ${ }^{15} \mathrm{NH}_{4} \mathrm{Cl}$ and supplemented glutamine or aspartate indicating the inhibition by these amino acids of the incorporation of ${ }^{15} \mathrm{~N}$ from ${ }^{15} \mathrm{NH}_{4} \mathrm{Cl}$ into formycin. It was of interest that glutamine and/or aspartate also

Fig. 2. Incorporation of ${ }^{15} \mathrm{~N}$ from ${ }^{15} \mathrm{NH}_{4} \mathrm{Cl}$ into formycin after 2 hours of the replacement culture Mass spectra were made with formycin isolated from GL-medium containing ${ }^{14} \mathrm{NH}_{4} \mathrm{Cl}$ (A) or ${ }^{15} \mathrm{NH}_{4} \mathrm{Cl}$ (B).

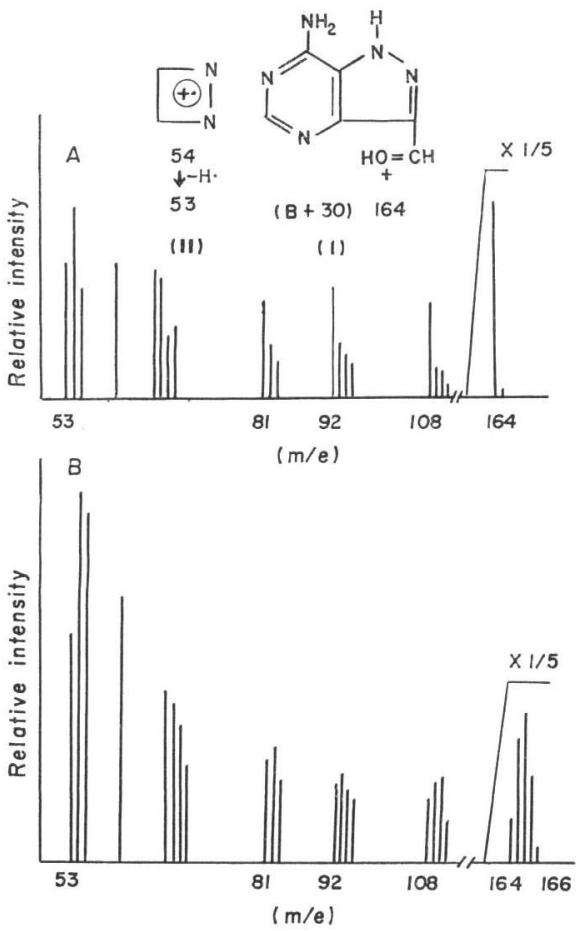

Fig. 3. Effect of glutamine or aspartate on the incorporation of ${ }^{15} \mathrm{~N}$ from ${ }^{15} \mathrm{NH}_{4} \mathrm{Cl}$ into formycin in 2 hours of the replacement culture

Mass spectra were made with formycin isolated from GL-medium containing ${ }^{15} \mathrm{NH}_{4} \mathrm{Cl}$ (A), ${ }^{15} \mathrm{NH}_{4} \mathrm{Cl}$ and $10 \mathrm{~mm}$ of glutamine (B) or ${ }^{15} \mathrm{NH}_{4} \mathrm{Cl}$ and $10 \mathrm{~mm}$ of aspartate (C).
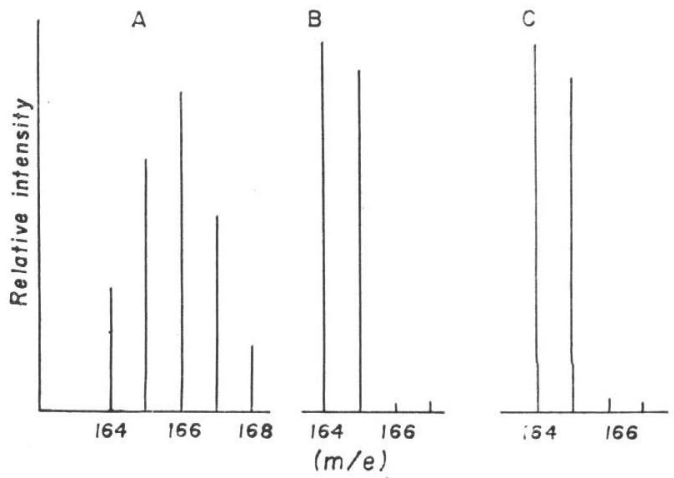

seemed likely to act as an efficient donor of nitrogen in the biosynthesis of formycin.

Incorporation and Distribution of Labeled

Ribose and Glucose into Formycin

To determine if ribose is the precursor for ribosyl moiety of formycin, experiments were 
Table 4. Incorporation and distribution of ribose and glucose into formycin after 2 hours of replacement culture

Ribose was added to GL-medium at a concentration of 10 or $0.1 \mathrm{~mm}$ for determination of percent incorporation or distribution, respectively.

\begin{tabular}{l|c|c|c|c}
\hline \multirow{2}{*}{$\begin{array}{c}\text { Labeled compound } \\
\text { used }\end{array}$} & $\begin{array}{c}\text { Percent } \\
\text { incorporation* }\end{array}$ & DFA-4 & $\begin{array}{c}\text { Percent distribution* of }{ }^{14} \mathrm{C} \text { in } \\
\text { ribose }\end{array}$ & $\begin{array}{c}\text { C-2' } \\
\text { in ribose }\end{array}$ \\
\hline$\left[\mathrm{U}-^{14} \mathrm{C}\right]$ Ribose & 3.1 & 2 & 18 & 80 \\
{$\left[1-{ }^{14} \mathrm{C}\right]$ Ribose } & $* *$ & 1 & 92 & 7 \\
{$\left[\mathrm{U}-14^{-14} \mathrm{C}\right]$ Glucose } & 51.6 & 26 & 20 & 54 \\
{$\left[1-{ }^{14} \mathrm{C}\right]$ Glucose } & 7.2 & 23 & 18 & 59 \\
\hline
\end{tabular}

* Calculated as described in Table 1.

** Experiment was not done.

done with the use of various labeled ribose and glucose. The data in Table 4 show that, although the incorporation of ${ }^{14} \mathrm{C}$ from $\left[\mathrm{U}_{-}{ }^{14} \mathrm{C}\right]$ ribose into formycin was lower than that of ${ }^{14} \mathrm{C}$ from $\left[\mathrm{U}-{ }^{14} \mathrm{C}\right] \mathrm{glucose}$, almost ${ }^{14} \mathrm{C}$ from $\left[\mathrm{U}-{ }^{14} \mathrm{C}\right.$ ] ribose was located at the ribosyl moiety of formycin and $18 \%$ or $80 \%$ of the radioactivity resided in carbon- $1^{\prime}$ or carbons $-2^{\prime}$ to $-5^{\prime}$ of the ribose, respectively. Moreover, ${ }^{14} \mathrm{C}$ from $\left[1-{ }^{14} \mathrm{C}\right]$ ribose was exclusively located at carbon- $1^{\prime}$ of ribosyl moiety of formycin. These results suggested that ribose was the direct precursor for the ribosyl moiety of the antibiotic. It is of interest, however, that the incorporation efficiency of ${ }^{14} \mathrm{C}$ from $\left[1-{ }^{14} \mathrm{C}\right]$ glucose into the ribosyl moiety was estimated to be similar to the efficiency of ${ }^{14} \mathrm{C}$ from carbons- 2 to -6 of glucose (in Table $4,51.6$ of the percent incorporation of ${ }^{14} \mathrm{C}$ from $\left[\mathrm{U}_{-}{ }^{14} \mathrm{C}\right.$ ]glucose is provisionally equivalent to 8.6 of that of ${ }^{14} \mathrm{C}$ from $\left[1-{ }^{14} \mathrm{C}\right]$ glucose). These results excluded the substantial formation of the ribosyl moiety via hexose monophosphate shunt or by the oxidative removal of carbon- 6 of glucuronic acid.

Effect of Adenine, DFA-4 or Pyrazofurin on Formation of Formycin

On the assumption that ribose is a direct precursor for ribosyl moiety of formycin, DFA-4 was added to GL-medium to examine whether the salvage synthesis of formycin occurs or not. The data shown in Table 5 demonstrated the inhibition of formycin biosynthesis by DFA4. 5-Amino-4-imidazolecarboxamide riboside (AICAR) and 5-amino-4-imidazole-N-succinocarboxamide riboside (SAICAR) did not inhibit the biosynthesis of formycin, while pyrazofurin, a C-ribonucleoside analog of AICAR, inhibited the biosynthesis. At a concentration of $1 \mathrm{~mm}$, adenosine, guanine, guanosine, hypoxanthine,

Table 5. Effect of DFA-4, pyrazofurin or adenine on formycin formation in replacement culture for 9 hours

\begin{tabular}{l|r|r|r}
\hline $\begin{array}{c}\text { Compound } \\
\text { added }\end{array}$ & $\begin{array}{c}\text { Concen- } \\
\text { tration } \\
(\mathrm{mm})\end{array}$ & $\begin{array}{c}\text { Formycin } \\
\text { produced } \\
(\mu \mathrm{g} / \mathrm{ml})\end{array}$ & $\begin{array}{c}\text { Inhibition } \\
(\%)\end{array}$ \\
\hline None & - & 38 & 0 \\
DFA-4 & 0.1 & 34 & 10 \\
& 1.0 & 26 & 32 \\
Adenine & 10.0 & 0 & 100 \\
& 0.1 & 37 & 3 \\
Pyrazofurin & 1.0 & 27 & 30 \\
& 10.0 & 17 & 55 \\
AICAR* & 10.0 & 23 & 40 \\
SAICAR** & 1.0 & 36 & 71 \\
\hline
\end{tabular}

* AICAR; 5-Amino-4-imidazolecarboxamide riboside.

** SAICAR; 5-Amino-4-imidazole-N-succinocarboxamide riboside. inosine, xanthine or xanthosine showed $21,16,16,18,18,16$ or 16 percent inhibition, respectively, and pyrimidine bases or nucleosides did not inhibit the biosynthesis of formycin. 


\section{Discussion}

From the data in Tables 1 and 2, one carbon in the chromophore moiety of formycin can be estimated to be derived from two carbons (carbon-2 and one of carbons- 3 to -5) of lysine. If this is true in this case, it may be possible to assume that the two carbons of lysine are incorporated into the chromophore moiety through symmetric intermediate including carbon-2 of lysine or an identical molecule formed from carbon- 2 and one of carbons- 3 to -5 of lysine. Although cadaverin, a related symmetric compound, has been known as a decarboxylated product of lysine, this compound seems unlikely to act as the symmetric intermediate by the following reasons. (1). Cadaverin could not substitute for lysine in formycin formation under the conditions of replacement culture. ${ }^{14)}$ (2). When carbon-2 of lysine is incorporated into formycin via cadaverin, carbon- 6 of lysine should be also incorporated. However, as described in the text, ${ }^{14} \mathrm{C}$ from $\left[6-{ }^{14} \mathrm{C}\right]$ lysine was not incorporated into formycin.

Incorporation- and distribution-patterns in Table 3, which were obtained from the experiments with labeled glutamate and organic acids related to tricarboxylic acid cycle, are probably explained by the assumption that carbon(s) from these organic acids are incorporated into formycin after conversion to glutamate (or $\alpha$-keto-glutarate) via the cycle. It is also suggested that glutamate is incorporated into formycin through a pathway other than that of degradation to $\gamma$-amino- $n$-butyrate.

In the biosynthesis of minimycin, a C-riboside antibiotic, IsONO and SUHADOLNIK reported that the distribution of ${ }^{14} \mathrm{C}$ in this antibiotic favored a seven-carbon sugar or an eight-carbon branched sugar as the carbon skeleton for the ribosyl moiety and carbons-4 and -5 (probably carbons- $4,-5$ and -6 ) of the oxazine moiety. To explain the synthetic mechanism, they proposed a pathway involving glycolytic and hexose monophosphate oxidative pathway. ${ }^{11)}$ If formycin occurs via the proposed pathway, the following presumptions may be possible with regard to the experiments described in this paper. (1). ${ }^{14} \mathrm{C}$ from $\left[1{ }^{-14} \mathrm{C}\right]$ ribose should be incorporated into carbon- $1^{\prime}$ of formycin. $(2) .{ }^{14} \mathrm{C}$ from $\left[\mathrm{U}-{ }^{14} \mathrm{C}\right]-$ ribose should be incorporated into the ribosyl moiety. (3). ${ }^{14} \mathrm{C}$ from $\left[1-{ }^{14} \mathrm{C}\right]$ glucose should be incorporated into carbon- $1^{\prime}$ and $-5^{\prime}$ at the ratio of $1: 1$. (4). The salvage synthesis of formycin from DFA-4 should not occur. The data shown in Tables 4 and 5 are consistent with presumptions 1, 2 and 4 . It is, however, in conflict with presumption 3 that, as shown in Table $4,{ }^{14} \mathrm{C}$ from $\left[1-{ }^{14} \mathrm{C}\right]$ glucose was incorporated into carbon- $1^{\prime}$ and carbon(s)-2' to $-5^{\prime}$ of formycin at a ratio of approximately $1: 3$. As one of the causes of the low values for percent incorporation of ${ }^{14} \mathrm{C}$ from $\left[\mathrm{U}-{ }^{14} \mathrm{C}\right]$ ribose into formycin, a low rate of uptake of ribose into mycelia was considered to be reasonable. The ratio of the rate of uptake of ribose to that of uptake of glucose was confirmed to be lower than one-thirtieth under the conditions of the replacement culture (data are not shown). These results, when considered with those described in the text, indicate that, although the possibility of formycin biosynthesis via the proposed pathway whereby minimycin occurs is difficult to be ruled out entirely, the possibility of the biosynthesis from ribose and such precursors for the chromophore moiety of formycin as lysine, glutamate and so on still seem likely. In any event, the more detailed studies on biosynthesis of the ribose moiety and the chromophore moiety, especially on carbon-3, are needed.

The inhibition of formycin formation by DFA-4 or pyrazofurin are shown in Table 5 suggesting that these compounds are not the precursors for the biosynthesis of formycin. In previous work, both the conversion of formycin B to formycin in replacement culture and the activity of formycin B aminating enzyme(s) were confirmed to be inhibited by DFA-4. ${ }^{15)}$ These results led us to estimate that formycin B may be accumulated in the presence of DFA-4. Experimentally, however, neither formycin B nor formycin was accumulated even when DFA-4 was added at the concentration of $10 \mathrm{~mm}$ indicating the possibility that, in addition to the inhibition by DFA-4 of formycin aminating enzyme(s), this compound inhibits the other step(s) of the biosynthesis of formycin.

Acknowledgments

The authors express their appreciation to Dr. Y. OKAMI of the Institute of Microbial Chemistry and Dr. K. Kawamura of the Central Research Institute of Meiji Seika Co., Ltd. for their helpful discussions. Their thanks are due to Dr. G. E. GuTowski of the Lilly Research Laboratories for his kind supply of a sample of pyrazofurin. 


\section{References}

1) Johnson, L. \& D. Söll: In vitro biosynthesis of pseudouridine at the polynucleotide level by an enzyme extract from Escherichia coli. Proc. Nat. Acad. Sci. 67: 943 950, 1970

2) Cortese, R.; R. Landsberg, R. A. V. HaAr, H. E. Umbarger \& B. N. Ames: Pleiotropy of his T mutants blocked in pseudouridine synthesis in t-RNA; Leucine and isoleucine-valine operons. Proc. Nat. Acad. Sci. 71: $1857 \sim 1861,1974$

3) Cortese, R.; H. O. Kammen, S. T. Spengler \& B. M. Ames: Biosynthesis of pseudouridine in transfer ribonucleic acid. J. Biol. Chem. 249: 1103 1108, 1974

4) Wigler, P. W.; B. Bindslve \& T. R. Breitman: Effects of 4-thiopseudouridine on the salvage pseudouridine by Escherichia coli cells. J. Carbohydr., Nucleosides, Nucleotides 1: 307 321, 1974

5) Breitman, T. R.: Pseudouridylate synthetase of Escherichia coli, correlation of its activity with utilization of pseudouridine for growth. J. Bact. 103: 264 265, 1970

6) Uematsu, T. \& R. J. Suhadolnik: Pseudouridine, isolation and biosynthesis of the nucleoside isolated from the culture filtrates of Streptoverticillium ladakanus. Biochemistry 11: 4669 4674, 1972

7) Elstner, E. F. \& R. J. Suhadolnik: Nucleoside antibiotics. Biosynthesis of the maleimide nucleoside antibiotic, showdomycin, by Streptomyces showdoensis. Biochemistry 10: 3608 3614, 1971

8) Elstner, E. F. \& R. J. Suhadolnik: Nucleoside antibiotic. Glutamic acid and acetate into the maleimide ring of showdomycin by Streptomyces showdoensis. Biochemistry 11: 2578 2584, 1972

9) Elstner, E. F. \& R. J. Suhadolnik: Effect of changes in the pool of acetate on the incorporation and distribution of ${ }^{13} \mathrm{C}$ - and ${ }^{14} \mathrm{C}$ labeled acetate into showdomycin by Streptomyces showdoensis. J. Biol. Chem. 248: $5385 \sim 5388,1973$

10) Elstner, E. F. \& R. J. Suhadolnik: Die Asymmetrie des Tricarbonsäurezyklus, aufgezeigt an Studien zur Biosynthse des Antibiotikums Showdomycin. Ber. Deutsch. Bot. Ges. 86: 381 392, 1973

11) Isono, K. \& R. J. Suhadolnik: The biosynthesis of the nucleoside antibiotics: Minimycin formation by Streptomyces hygroscopicus. Ann. New York Acad. Sci. 255: 390 401, 1975

12) Kunimoto, T.; T. Sawa, T. Wakashiro, M. Hori \& H. Umezawa: Biosynthesis of the formycin family. J. Antibiotics 24: 253 258, 1971

13) Sawa, T.; Y. Fukagawa, I. Homma, T. Wakashiro, T. Takeuchi, M. Hori \& T. Komai: Metabolic conversion of formycin B to formycin A and oxoformycin in Nocardia interforma. J. Antibiotics 21: 334 339,1968

14) Ochi, K.; S. Iwamoto, E. Hayase, S. Yashima \& Y. Okami: Biosynthesis of formycin. Role of certain amino acids in formycin biosynthesis. J. Antibiotics 27: 909 916, 1974

15) OCHI, K.; S. Yashima \& Y. EGUCHI: Biosynthesis of formycin. Formation of formycin from formycin B. J. Antibiotics 28: 965 973, 1975

16) Kawamura, K.; S. Fukatsu, M. Murase, G. Koyama, K. Maeda \& H. Umezawa: The studies on the degradation products of formycin and formycin B. J. Antibiotics, Ser. A 19: $91 \sim 92,1966$

17) Емміск, R. D.: Resolution of lysine. U. S. Pat. 2,556,907, 1951

18) Townsend, L. B. \& R. K. Robins: The mass spectra of formycin, formycin B and showdomycin. Carbon linked nucleoside antibiotics. J. Heterocycl. Chem. 6: 459 464, 1969 